\title{
Reading Aloud as a Leading Activity With Preschool Students
}

\author{
Pradita Nambiar and Sharada Gade
}

\begin{abstract}
We examine a teacher's read-aloud activity with her preschool students in India. Three vignettes show how this leading activity helps young children take part in socio-dramatic play, fostering their culturalhistorical development. Collaborating as teacher and researcher, we consider students' use of words, instances of object substitution, and exploration of social roles in the story being read aloud, to demonstrate the development of their higher psychological activity. Moreover, we contend that read-aloud activities in preschool are crucial for developing student learning during middle childhood.
\end{abstract}

\section{Background}

Read-aloud activities for preschool children are prevalent in many schools worldwide. One can imagine a teacher sitting next to a group of children, reading aloud from large picture books. A cat here, a ball there, a parent, a tree, a friend, blue skies, and mountains fill these colourful pages with accompanying text. The children being read to are gradually introduced to various aspects of the human world they inhabit, which they start to become aware of and transform in different ways. Through reading aloud and/or storytelling with four-year-old students, the teacher is seemingly in complete control of the mood, tempo, drama, and atmosphere in the classroom. Eagerness, wonder, doubt, excitement, and priceless expressions emerge- enough to take one's breath away. It is not uncommon for a visiting parent to sit beside in silence, and learn a trick or two from this wondrous experience. However, it is the development of children's potential, which results from this pedagogical activity, that we are examining in this paper. In doing so, we draw on the neo-Vygotskian construct of a leading activity, which maintains that at various stages of children's development, different kinds of activity can play a vital role in awakening, bringing about, and leading cultural-historical development (Karpov, 2003). When read to by preschool teachers, socio-dramatic play, as a leading activity, helps three- to six-year-olds become interested in the world of human relations.

We examine notions of reading aloud and leading activity in the sections that follow, but first provide more context for our study. As a teacher, Pradita's read-aloud activities with preschoolers set the stage for her reflections as a practitioner. These experiences were followed by her journal entries which inform the three vignettes we present as data. As a researcher with her own understanding of child development, Sharada had opportunity to collaborate with Pradita, in line with Vygotskian cultural historical activity theory or CHAT perspectives (e.g., Gade \& Blomqvist, 2015). As our collaboration as teacher and researcher developed over time, we gained from sharing experiences, discussing relevant literature, and reflecting on the various actions we would take as practitioners. Thus, we gained an appreciation of what Hollingsworth et al. (1993) call relational knowing. Putting Pradita's students front and centre, such 
knowing drew on relationships with ourselves, each other, our lived experiences, as well as our existential reality. We used relational knowing as a valuable tool for our collaborative learning.

Employed in the fields of teacher preparation and teacher learning, the concept of relational knowing could provide a space to help resolve the tension between acquiring knowledge of what schooling presently is and what it should and might be (the lived world and the theoretical world). (Hollingsworth et al., 1993, p. 10)

In our study of students' cultural-historical development, in which reading aloud is considered a leading activity, we first drafted sections of this paper that each of us was comfortable writing. Redrafting earlier sections along the way, we then viewed the entirety of our writing from our respective positions as practitioners. This led to the present text, which represents relational knowing and collaborative learning, and leads to the following question: "How does the neo-Vygotskian construct of a leading activity shed light on the cultural-historical development of preschool students as they participate in the pedagogical practice of reading aloud?"

\section{Reading Aloud, Storytelling}

Pradita's kindergarten classroom of four- to five-year-olds is tucked away under the shade of a gigantic banyan tree. With its well-concealed hollow and loose hanging roots, this magnificent tree has been witness to many a story read aloud to her children. Every morning, after playing a game with their friends outdoors, Pradita's students rush into her cave-like room next to the banyan tree. They leave their footwear outside and try to sit as close to Pradita as possible. This is where curiosities are aroused, fantasies come alive, characters switch roles, problems are resolved, and fears and feelings are expressed. Pradita sits on a chowki, or low stool, and holds up a book she has kept ready for the day. The books she chooses keep the children focused on the many creative ways in which words and sounds are used. While the plots of most of these books are simple, she looks forward to having deeper conversations with her students and listening to their interpretation of the story. Next, children look at the pictures and text of her book, resulting in enthusiastic chatter. While some students want to know the name of the story, others try to read the title. Some say they have that same book at home, while a few try to adjust their tiny bodies to get the best view of the book and their teacher. Pradita makes sure that all the students can see the book, and rearranges where they are seated, if needed. She knows that holding up the book is critical for children to make connections between the illustrations they see and the story they hear. Lasting about 20 minutes each morning, Pradita's read-aloud sessions help promote vocabulary development, phonological awareness, and the very act of reading.

Research on storytelling and reading aloud sheds light on why so much time is spent in preschool classrooms on these absorbing activities. Both activities are led by adults: the teacher at school or a parent at home. Meyer et al. (1994), however, state that while storytelling depends on the language register and speech of the storyteller, the teacher is the one who mediates the text and brings about a shared context for the young learner when reading aloud. Moreover, Ammon (1974) points out that, beyond mere entertainment, the teacher's role is to evaluate the reading progress learners make. One need not feel guilty about the pleasure of reading aloud, adds Butler (1980), as this activity motivates 
children to become independent readers. She advises teachers to read at a level above children's current reading level, acknowledging that the benefits of reading aloud correlate to how frequently they are read to. As a teacher, Schmitt (2016) introduces voices, tones, and facial expressions when reading aloud and underscores their key role,

Students who are equipped with a plethora of reading strategies will be able to comprehend any material or resource they are reading whether it's a historical fiction novel about the Great Depression, a science textbook covering a chapter on Newton's laws of motion, or a magazine article instructing how to make a delicious chocolate cake. (p. 373)

In addition, two authoritative voices weigh in on the importance of storytelling. First, is American researcher Vivian Paley (1986), who tape-recorded, listened to, and transcribed her own storytelling sessions, in order to figure out what children made of them. According to Paley, each child was attempting to answer the following questions: "What is going on in this place called school, and what role do I play here?" Paley maintains that school begins to make sense to children when they pretend it is something else. Second, is Indian academic Krishna Kumar (2011), who highlights three key aspects in relation to the pedagogical practice of storytelling: promote good listening, be a good listener, and personally experience, by proxy, some pattern, plot, or design which is satisfying in our otherwise chaotic world. He adds that a great many of life's challenges can only be met orally, for which we need to prepare our children.

Literature on the nitty-gritty of reading aloud is just as insightful. Van Kleeck (2008) stresses the need for teachers' reading to go beyond the information in the text being read, so as to guide preschoolers' development of oral language skills, which are valuable for their own reading comprehension. Where appropriate, questions such as, "Was that a good thing to do? Is that what we usually do?", help teachers to foster students' ability to infer-and provide responses to-what might be happening in any story. According to Hoffman (2011), using this strategy allows students to understand the motivation of characters in the story, a skill essential for them to participate more fully in society. Pagan and Senechal (2014) point out the opportunities students have of using words they hear during read-aloud sessions, both by direct reference to them and by inferring their meaning from the larger context of what is read. Based on their study of municipal schools, Brodin and Renbald (2020) stress that reading aloud, in itself, does not improve children's communication, unless preschool staff follow up such activities with discussions and reflections on the content. This enables children to express themselves in their own words and become conscious of their own language. Damber (2014) affirms that effective reading aloud not only promotes knowledge about language and the world at large, but also the formation of individual student identities. Meanwhile, Fox (2013), a writer of children's literature, views story-reading sessions as a way to create a collective identity, similar to that of a family, in which the members have secret joys that come from shared experiences. 


\section{Socio-Dramatic Play: Leading Activity}

Through the neo-Vygotskian construct of a leading activity, Karpov (2003) draws attention to the fact that different kinds of activity can be very powerful in awakening or leading the cultural-historical development of children. By participating in a leading activity, children develop new motives, enabling them to transition from one developmental period to the next. For example, in the first year of a child's life, emotional communication with caregivers is a leading activity for infants. At this stage, children become interested in the world around them, and come to accept adult caregivers as mediators of all their relationships with the outside world. Similarly, in the second and third year of a child's life, objectcentred activity is a leading activity for toddlers. By participating in this activity, children find the need to communicate about various objects, and learn active speech, which results in leading the development of all their psychological functions. They also begin to use objects shown to them by adults, such as feeding themselves and their doll with a spoon. In taking such actions, children display independence and develop symbolic thought. These outcomes prepare children to transition to socio-dramatic play, a leading activity for the early childhood period of three- to six-year-olds, in which children develop an interest in the world of human relations. With the adult world becoming more enticing, children begin to explore the many social roles that adults introduce and mediate for them. As they begin to follow the rules that come along with the roles of a doctor or train conductor, children implicitly obey social rules. They accept that postmen have to ring the doorbell to deliver mail, and that doctors wear white lab coats at work. Children thus begin to self-regulate their own behaviour and are able to align their point of view with those of others. With respect to this stage of leading activity, Karpov reiterates Vygotskian scholar Daniel Elkonin's argument, that the outcome of socio-dramatic play as a leading activity, is that children realize they are not yet adults, and must go on to study at school. Learning in instructional settings is the leading activity that middle childhood students undertake, when they learn how to organize concepts of everyday items that are familiar to them, such as bananas or grapes.

We view Pradita's read-aloud sessions and accompanying socio-dramatic play as Karpov's leading activity, where she has opportunity to mediate the world of adult social relationships that children are interested in, one story at a time. Apart from the sheer excitement that comes with roaring like a lion or tweeting like a bird, there is an opportunity for her to introduce words that students can use in relevant contexts. Her dramatization of words such as "scowl," "anger," or "red in the face," is another example of her being able to lead students' development. In a Vygotskian sense, these words are psychological tools she makes students conscious of, which they can use in appropriate ways while interacting with others in their surrounding culture. Such an ability to use words, whose meaning is acquired via didactic change over time during social collaboration, signals the development of higher psychological activity. Socio-dramatic play thus leads students' cultural-historical development. On occasion, Pradita has asked her students if they have seen an angry policeman or a happy one, or even one wearing plain clothes. In responding to such questions, students display self-regulation. Pretending the classroom to be a tiger's cave or a queen's palace while reading aloud, makes object substitution possible for students-another aspect that Karpov highlights. And then there are students whose appetite for the make-believe is quenched. Displaying boredom, their behaviour indicates their readiness to transition to the next 
leading activity that is best suited to middle childhood. Vygotsky viewed children's play, including socio-dramatic play, as a rich source of awakening their cultural-historical development, enabling students to be "a head taller than themselves." Yet, it is in his focus on imagination with respect to children's play, where we find additional insight. Vygotsky (1978) asserts,

Towards the beginning of preschool age, when desires that cannot be immediately gratified or forgotten make their appearance and the tendency to immediate fulfilment of desires, characteristic of the preceding stage, is retained, the child's behaviour changes. To resolve this tension the preschool child enters an imaginary, illusory world in which the unrealisable desires can be realised and this world is what we call play. Imagination is a new psychological process for the child, it is not present in the consciousness of the very young child, is totally absent in animals, and represents a specifically human form of conscious activity. Like all functions of consciousness, it originally arises from action. (p. 93)

These features allow us to regard Karpov's assertion that, mediated by adults, children's development turns into in socio-dramatic play, which is oriented towards the external world. When such a mediated process matures, resulting in development of new motives, students are ready to move on to their next leading activity: learning in middle school settings.

Two authors offer valuable starting points for further examining Vygotsky's notion of play. Bodrova and Leong (2015) value socio-dramatic play as make-believe play, in which preschoolers are capable of intentional behaviour on their way to self-mastery. Recognizing socio-dramatic play as a leading activity, they point to students being able to take on and act out roles, which, in turn, demands that rules associated with these roles be followed by them. Extending Paley's insights into storytelling or story-acting by preschoolers, Nicolopoulou et al. (2010) focus on the narrative dimension involved, and draw attention to preschoolers having the opportunity for gaining, as well as demonstrating, social, narrative, interactional, and emotional competencies. We argue such a collective canvas for children's cultural-historical development corresponds to what Pradita was able to achieve through reading aloud and/or storytelling with four-year-olds in her preschool classroom. We now present three vignettes rendered in her own voice, in which she refers to her students by the pseudonyms she chose, to reflect how reading aloud improved their social interactions.

\section{Pradita's Vignettes}

In my first vignette, the school year had just begun and I had 23 four-year-olds sitting on the floor around me. The children had just returned to school after a two-month summer break. Understandably, many of them were missing their parents and their home. I decided to read Jillian Harker's (2009) book, I Love You Mummy, since it is about a young bear whose mother teaches him how to fish, swim, climb trees, pick fruits, and play. In this story, the little bear wants to try out new experiences and doesn't want his mother's advice. But when he is unable to do things on his own, the mother teaches him everything he needs to know in order to be a well-rounded bear. I chose Harker's story to endear my students to me as their teacher, and also help them verbalize experiences they might have had at home. In addition, I wanted them to share the many things they learnt from their own mother during their recent summer holidays. Our reading went as follows: 
Pradita: (Holding up the book for all to see). What did your mother teach you?

Rumi: (Standing on one leg and trying to balance) Mamma taught me to balance.

Ashok: Mummy taught me to paint.

Pradita: You know in this story, the mother bear is teaching the baby bear to play gently.

Pradita: (Reading from the book). Be gentle when you play.

Pradita: What does gentle mean?

Ajay: No fighting!

Anya: No kicking!

Shiv: No punching!

Pradita: Yes, That's right, we do not do all this when we are gentle. So then what do you do when you are gentle?

All: (Children peer into the book trying to look for a clue to respond to the question)

Pradita: What are the mother and the baby bear doing in the picture?

Ajay: They are holding hands and walking. They are also rolling in the grass and laughing.

Anya: I hold hands with my friend and walk. (She demonstrates the same for me)

Shiv: I put hands on my friend's shoulder like this. (He shows the same with his friend)

Pradita: So when you are gentle, you hold hands, put your arms around your friend's shoulder or just roll in the grass.

This reading-aloud session ended with children carrying out many actions, including those which showed me that they had understood what the word "gentle" meant, exhibited by hugging or being affectionate with one another. They even started to walk away from me, holding each other's hands, and also walking shoulder to shoulder. I had to call the children back to me, so that I could continue reading my story.

In reading Harker's book, Pradita prompts her students to consciously examine the word gentle and consider its meaning, rather than what her students thought the word was not. This helped motivate her students to animate the word by dramatizing it. Pradita's mediation of this word created a shared context with her students, who demonstrated that they understood its meaning. The creation of an imaginary situation for gentleness in her reading-aloud session allowed the children to act out its meaning with their friends and demonstrate actions they associated with being gentle. By exploring the world presented to them, her students' performance was intentional and demonstrative of having understood what being gentle meant. In addition, they were able to associate the word with a broad category of situations. When Pradita's students walked away holding each other's hands, they were co-constructing the meaning of gentle by acting it out and were exhibiting a collective identity (Fox, 2013) of being a group of gentle people. Pradita's reading aloud was thus able to awaken or lead her students' understanding of the word, which, according to Vygotsky, was indicative of their development of higher psychological activity.

My second vignette depicts the importance of children learning to make and keep friends. As a preschool teacher, I would observe children coming to school each morning and putting their bags to one side. In doing so, they would always be on the lookout for bags that belonged to their best friend. Moreover, if a child discovered that their best friend had not turned up, since their bag was not there, they were often sad for the entire day. With this in mind, I read them a story on friendship that drove home the point that one could make new best friends, too. This time, I read Klaus Baumgart's (2013) book, Lenny and Tweek Wanted: A Friend. This story is about a little mouse named Lenny, who puts up a tiny notice in order to 
make a new friend. A little bird Tweek comes along and gives him company, and does all the things two friends are supposed to do. The story's message is that, even though you may be looking for a specific friend, those with whom you appreciate the simple joys of everyday living are also your friends. I chose to read this story while sitting outdoors on the steps approaching the classroom, to re-create the feeling of the open field that was present throughout the book. I played the role of Tweek and used my tone to tweek like a little bird, and did all the things that Tweek did with his friend Lenny. The following exchange ensued:

Rohan: I think it's a boy because Lenny is wearing shoes.

Pradita: But girls also wear shoes. See, Arti, Priya and Usha are also wearing shoes. (Pointing to the girls in the class)

Priya: But Lenny has short hair. My daddy also has short hair and wears a dress like Lenny. (She looks at the picture and points to the dress)

Anuj: Lenny is playing with a ball.

Pradita: But the girls in the class wear a T shirt and shorts like Lenny and they also play with ball.

Rohan: Teacher, you can be my friend.

Pradita: Of course, I am your friend Tweek. (I tweeked and the class roared with laughter)

Pradita: (Finally, reading the last line) And sometimes they stay for good.

Pradita: Lenny and Tweek became friends forever.

Priya: (standing up and saying) Arti and I are friends forever.

In this session, a boy named Rohan spontaneously agreed to be Tweek's friend, the role I took on as teacher. His playing Lenny was not part of the story as such, but had to do with pretending that our classroom was the caravan where the story played out. Rohan was exploring the role of being a frienda notion I mediated as teacher. The earnestness and sincerity which Rohan brought to his role seemed to convey his interest in the world of human relations. He felt free to accept his much older teacher as his friend, and the teacher's open, accepting, and encouraging response created a shared cultural identity in which she and the student became friends. As asserted by Damber (2014), Rohan was creating his individual identity as a friendly person. I also noticed that another girl, Priya, was able to use the word forever in the context of the same story and view the notion of friendship in a more extended sense of time, indicative of her own grasp of the story.

Moreover, Pradita mediated the text by presenting the social role of a friend. She tweeked like a little bird, called herself by the bird's name in the story, and emphasized the word forever, explaining its significance in relation to human friendship. Merely taking on the role of Tweek would have been inadequate and made the act immature. However, her use of forever enriched the read-aloud activity and transcended the time limits often associated with preschoolers. Pradita's reading aloud awakened, or led the development of, Priya's conscious use of the word forever. Priya's expressive vocabulary and inference of the meaning of this word was made possible via the social interaction during Pradita's readaloud session. The inclusion of this new word in relation to the story-together with Priya's inferring its meaning and using the word aloud-were indicative of her becoming conscious of her own language (Brodin \& Renbald, 2020). In addition to her communicating the meaning of the word forever, Priya's 
expressing her thoughts is something Vygotsky would view as her ability to interiorize, organize, and self-regulate her own behaviour-an act he would view as being uniquely human.

My third and final vignette focuses on the importance of children finishing what they have started. This was based on observing children take part in and complete various activities, such as working with play dough, building sand castles, cutting papers and making a collage, as well as learning to read and write. However, there was a particular child in my class who would invariably leave his work half done. I spent a lot of time cajoling and coaxing him to finish his work, and decided to read the Donald Moyle's (1981) story, The Girl Who Half Did Things, about a girl with good intentions who left things half done. As soon as I mentioned the title of the story, the following exchange transpired:

Ajay: I know, I know the story is about Shankar.

Shankar: No, it's not about me.

Pradita: Yes, it's not about Shankar, but about a girl who always did not complete her work.

Pradita: Crash! She dropped a plate. (I read the part from the book)

Rehan: Now her mother will shout at her.

Pradita: What would it have been made of, that the dishes broke when they fell?

Ajay: I think it is made of glass.

Priya: Now it will poke the leg.

Rehan: When my brother dropped a glass it made a lot of noise. (He covered his ears as though he could hear the sound of glass crashing.)

During this discussion, I found that Shankar, whose behaviour had prompted me to read the story, had distanced himself from the character portrayed in the story, as somebody who half did things. Fortunately, Shankar felt reassured that the story was not about him, but about another girl.

Pradita's heightened tone with the word Crash! conveyed a mental image of dishes falling, enabling Rehan to envision this scene and merge his personal view with that of the author. It turns out that Rehan had previously dropped and broken dishes in his own life, so he could strongly identify with the girl being reprimanded in the story. By referring to a past event, Rehan was able to infer relevant aspects based on his prior experiences, which underscored the importance of memory in his psychological functioning. Pradita's question about what the dishes were made of motivated Priya to visualize the connection between broken dishes and hurting one's legs (i.e., "Now it will poke the leg"). Thus, Priya was demonstrating an act of self-regulation. Priya and Rehan's comments show that they were anticipating the repercussions of the act of breaking a plate: Rehan imagined the broken dishes would make the girl's mother angry, while Priya felt that the broken glass might hurt her and cause pain. Such acts of imagination, thinking, and reflection display students' ability to function in a complex environment and face challenges in their future lives. 


\section{Discussion}

Reading aloud to her students has allowed Pradita to collect a sizeable library from which she instinctively pulls out stories that suit her purposes. She finds the experience of reading aloud gratifying, and that it puts her in the right frame of mind for the rest of the school day. As evidenced in the three vignettes, Pradita finds that children become active participants in the stories, as if it were a game, a make-believe play in which both she and the students lose their identities and share a common surreal experience. As maintained by Paley (1986), teaching preschoolers becomes more enriching when the classroom is treated as an imaginary place in which everybody can act out different roles. Moreover, as pointed out by Kumar (2011), by listening, students experience characters and situations that they may not have previously encountered in their lives. However, participating in the activity of reading stories and make-believe play is not enough on its own. When mediated by the teacher, play is learning, interwoven with drama, modulation, the raising and lowering of the pitch of the teacher's voice, and exploring the various social roles depicted in stories. In their 2010 study, Nicolopoulou and colleagues assert that by participating in role-plays and read-aloud sessions, children develop the capacity to be gentle, make lasting friendships, and anticipate what adults might say, all of which are necessary social competencies. By reading aloud to them, Pradita's preschoolers were able to access a world that was beyond their immediate experience. She thus finds reading aloud and/or storytelling to be vital for children's development-and not an activity that should be easily dismissed in favour of what is often erroneously perceived as the real business of learning in preschool. At its very core, reading aloud is undeniably developmental.

\section{References}

Ammon, R. (1974). Reading aloud: For what purpose? The Reading Teacher, 27(4), 342-346.

Baumgart, K. (2013). Lenny and Tweek wanted a friend. Pratham Books.

Bodrova, E., \& Leong, D. J. (2015). Vygotskian and Post-Vygotskian views on children's play, American Journal of Play, 7(3), 371-388.

Brodin, J., \& Renblad, K. (2020). Improvement of preschool children's speech and language skills. Early Child Development and Care,190(14), 2205-2213.

Butler, C. (1980). When the pleasurable is measurable: Teachers reading aloud. Language Arts, 57(8), 882-885.

Damber, U. (2014). Read-alouds in preschool - A matter of discipline? Journal of Early Childhood Literacy, 15(2), 256-280.

Fox, M. (2013). What next in the read-aloud battle? Win or lose? The Reading Teacher, 67(1), 4-8.

Gade, S., \& Blomqvist, C. (2015) From problem posing to posing problems by way of explicit mediation in Grades four and five. In F. M. Singer, N. Ellerton \& J. Cai (Eds.) Mathematical problem posing: From research to effective practice (pp. 195-213). Springer. 
Harker, J. (2009). I love you, mummy. Parragon.

Hoffman, J.L. (2011). Coconstructing meaning-interactive literary discussions in kindergarten read-alouds. The Reading Teacher, 65(3), 183-194.

Hollingsworth, S., Dybdahl, M., \& Minarik, L. T. (1993). By chart and chance and passion: The importance of relational knowing in learning to teach. Curriculum Inquiry, 23(1), 5-35.

Karpov, Y. (2003). Development through the lifespan: A Neo-Vygotskian approach. In A. Kozulin, B. Gidnis, V. Agayev, \& S. Miller (Eds.), Vygotsky's educational theory in cultural context (pp. 138-155). Cambridge University Press.

Kumar, K. (2011). Storytelling. What is the use? In K. Kumar (4th edition), What is worth teaching? (pp. 70-80). Orient Blackswan.

Meyer, L. A., Wardrop, J. L., Stahl, S. A., \& Linn, R. L. (1994). Effects of reading storybooks aloud to children. The Journal of Education Research, 88(2), 69-85.

Moyle, D. (1981). The girl who half did things. Holt, Rinehart and Winston Ltd.

Nicolopoulou, A., Barbosa de Sá, A., Ilgaz, H., \& Brockmeyer, C. (2010) Using the transformative power of play to educate hearts and minds: From Vygotsky to Vivian Paley and beyond. Mind, Culture, and Activity, 17(1), 42-58.

Pagan, S., \& Senechal, M. (2014). Involving parents in a summer book reading program to promote reading comprehension, fluency and vocabulary in Grade 3 and Grade 5 children. Canadian Journal of Education, 37(2), 1-31.

Paley, V. (1986). On listening to what the children say. Harvard Educational Review, 56(2), 122-132.

Schmitt, C. (2016). The importance of using voice when reading aloud to students. The Reading Teacher, 70(3), 373.

van Kleeck, A. (2008). Providing preschool foundations for later reading comprehension: The importance of and ideas for targeting inferencing in storybook-sharing interventions. Psychology in the Schools, 45(7), 627-643.

Vygotsky, L. S. (1978). Mind in society: The development of higher psychological processes. Harvard University Press. 


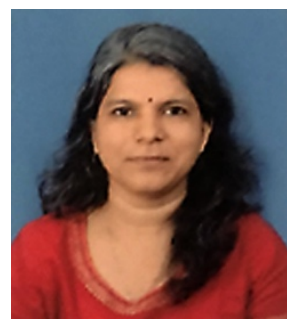

Pradita Nambiar is a teacher at Vidyaranya High School, Hyderabad, India, where she has taught preschool and primary grades for almost a decade. She holds a Masters in Elementary Education from Tata Institute of Social Sciences (TISS), Mumbai, India, where her thesis was titled, "Study of the epistemological presuppositions and curricular dimensions of the practice of theme-based learning in a tribal school in Tamil Nadu." Her collaboration with Sharada Gade is an attempt to share her work and initiate reflection with other teachers.

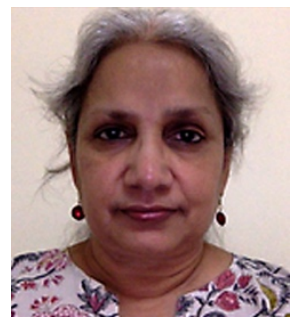

Sharada Gade is an independent researcher in Hyderabad, India, and a Visiting Faculty member at the Tata Institute of Social Sciences (TISS). Following doctoral work in Norway, she has held postdoctoral fellowships in India, Sweden, the United States, and the United Kingdom. Her work focuses on understanding the developmental aspects of instructional practices in line with cultural historical activity theory or CHAT perspectives, on which she collaborates actively with teachers. 